\title{
Soy isoflavone glycitein protects against beta amyloid-induced toxicity and oxidative stress in transgenic Caenorhabditis elegans Astrid Gutierrez-Zepeda1 ${ }^{1}$, Ross Santell ${ }^{2}$, Zhixin Wu${ }^{1}$, Marishka Brown ${ }^{1}$, YanJue $\mathrm{Wu}^{1}$, Ikhlas Khan ${ }^{3}$, Christopher D Link ${ }^{4}$, Baolu Zhao ${ }^{5}$ and Yuan $\mathrm{LuO}^{* 1,6}$
}

\begin{abstract}
Address: ${ }^{1}$ Department of Biological Sciences, University of Southern Mississippi, Hattiesburg, MS 39406, USA, ${ }^{2}$ Department of Human Sciences, Alcorn State University, Alcorn, MS 39096, USA, ${ }^{3}$ National Center for Natural Products Research, School of Pharmacy, Oxford, MS 38655, USA, ${ }^{4}$ Institute for Behavioral Genetic, University of Colorado, Boulder CO 80309, USA, ${ }^{5}$ Laboratory of Visual Information Processing, Center of Brain \& Cognitive Science, Institute of Biophysics, Academia Sinica, Beijing 100101, P.R. China and ${ }^{6}$ Department of Pharmaceutical Science, School of Pharmacy, University of Maryland, Baltimore, MD 21201-1180, USA

Email: Astrid Gutierrez-Zepeda - atita79@yahoo.com; Ross Santell - rsantell@lorman.alcorn.edu; Zhixin Wu - zhixinwu123@yahoo.com; Marishka Brown - mkbrown3772@yahoo.com; YanJue Wu - yj_w2000@yahoo.com; Ikhlas Khan - ikhan@pop.olemiss.edu; Christopher D Link - linkc@ibg.colorado.edu; Baolu Zhao - zhaobl@sun5.ibp.ac.cn; Yuan Luo* - yluo@rx.umaryland.edu

* Corresponding author
\end{abstract}

Published: 25 August 2005

BMC Neuroscience 2005, 6:54 doi:10.1 186//47/-2202-6-54

This article is available from: http://www.biomedcentral.com/I47/-2202/6/54

(c) 2005 Gutierrez-Zepeda et al; licensee BioMed Central Ltd.

This is an Open Access article distributed under the terms of the Creative Commons Attribution License (http://creativecommons.org/licenses/by/2.0), which permits unrestricted use, distribution, and reproduction in any medium, provided the original work is properly cited.
Received: 02 February 2005

Accepted: 25 August 2005

\begin{abstract}
Background: Epidemiological studies have associated estrogen replacement therapy with a lower risk of developing Alzheimer's disease, but a higher risk of developing breast cancer and certain cardiovascular disorders. The neuroprotective effect of estrogen prompted us to determine potential therapeutic impact of soy-derived estrogenic compounds. Transgenic $C$. elegans, that express human beta amyloid $(A \beta)$, were fed with soy derived isoflavones genistein, daidzein and glycitein $(100 \mu \mathrm{g} / \mathrm{ml})$ and then examined for $A \beta$-induced paralysis and the levels of reactive oxygen species.
\end{abstract}

Results: Among the three compounds tested, only glycitein alleviated $A \beta$ expression-induced paralysis in the transgenic $C$. elegans. This activity of glycitein correlated with a reduced level of hydrogen peroxide in the transgenic $C$. elegans. In vitro scavenging effects of glycitein on three types of reactive oxygen species confirmed its antioxidant properties. Furthermore, the transgenic $C$. elegans fed with glycitein exhibited reduced formation of $\beta$ amyloid.

Conclusion: These findings suggest that a specific soy isoflavone glycitein may suppress $A \beta$ toxicity through combined antioxidative activity and inhibition of $A \beta$ deposition, thus may have therapeutic potential for prevention of $A \beta$ associated neurodegenerative disorders.

\section{Background}

Estrogen, a natural steroid long associated with effects on the female reproductive system, also plays a role in the central nervous system (CNS) through binding estrogen receptors located in the brain $[1,2]$. It has been demon- strated that estrogen has neuroprotective and neurotrophic properties [1-9]. Epidemiological studies suggest that post-menopausal women using Estrogen Replacement Therapy (ERT) have a decreased risk of developing dementia [10-12]. However, the beneficial effect of ERT 
on dementia associated with Alzheimer's disease (AD) is yet inconclusive [13-15]. Although ERT alleviates the symptoms associated with menopause and has positive effects on bones, ERT in post-menopausal women has been linked to a higher incidence of uterine and breast cancer. Consequently, the Selective Estrogen Receptor Modulators (SERMs) compounds that exert tissue specific estrogenic effects may provide the benefits of ERT without the risks. A group of natural SERMs are the soy-derived phytoestrogens, which are structurally similar to estrogen [16], and may serve as an alternative to ERT [17-19].

Soybeans contain a large amount of isoflavones, including genistein (4', 5'7-trihydroxyisoflavone), daidzein (4', 7-dihydroxyisoflavone), glycitein (6-methoxydaidzein) and their glycosides [20]. Experimental evidence suggests that soy isoflavones possess many properties including estrogenic [16], antioxidant [21] hypocholesterolemic [22], and inhibition of cell proliferation and DNA synthesis $[23,24]$. Phytoestrogens exert estrogen agonist and antagonist characteristics [17], in part because of differential binding affinities for the estrogen receptor (ER) isoforms; with higher affinity for ER $\beta$ than for ER $\alpha$. Areas of the brain responsible for cognitive function and susceptible to AD (basal forebrain, hippocampus, cerebral cortex), express higher levels of ER $\beta$ compared to ER $\alpha$ [25]. Thus, interest in these compounds has grown because they could be used as SERMs, to delay or prevent the cognitive decline associated with $\mathrm{AD}[3,26]$ without increasing the risk of developing cancer [27].

$\mathrm{AD}$ is widely recognized as a serious public health problem [28]. The clinical symptoms of AD begin with memory impairment that eventually progresses to dementia, a process postulated to be the consequence of selective degeneration of nerve cells in those brain regions critical for memory, cognitive performance and personality [29]. $\mathrm{AD}$ is characterized by the presence of amyloid beta peptide $\left(A \beta_{1-42}\right)$ aggregation and increased oxidative stress, both causing neuronal injury and death [30]. An "amyloid cascade" hypothesis states that accumulation of $\mathrm{A} \beta$ deposition initiates a series of downstream neurotoxic events, which result in neuronal dysfunction and death [31]. The strongest evidence supporting this hypothesis comes from molecular genetic studies. Patients with Down's Syndrome, a disease related to an extra copy of chromosome 21 containing the APP gene, develop AD with the formation of $A \beta$ deposits, an early sign of brain lesion [32]. All familiar forms of AD (FAD)-linked mutations, in the APP gene or two presenilin genes (PS1 and PS2), result in increased production of $A \beta_{42}$, which is the more amyloidogenic form [33]. Transgenic mice overexpressing the mutant APP develop A $\beta$-containing amyloid plaques similar to those found in AD. Furthermore, inducing toxicity and cognitive dysfunction by introduc- ing $A \beta$ into organisms that do not have endogenous $A \beta$ $[34,56]$ provided "gain of function" evidence for the "amyloid hypothesis". In addition, other structure lesions including neurofibrillary tangles and AproE might contribute to an imbalance between $A \beta$ production and clearance [31]. Therefore, modulation of $A \beta$ production and clearance in the brain is one approach for treatment of $\mathrm{AD}$.

In order to understand the neuroprotective mechanism of phytoestrogens, we performed several experiments using a transgenic Caenorhabditis elegans model expressing the human amyloid-beta peptide $\left(A \beta_{1-42}\right)$. The transgenic $C$. elegans exhibits $\beta$ amyloid fluorescence staining similar to those observed in the human brain [34], along with a concomitant progressive paralysis phenotype [35]. Results of these experiments suggest that the neuroprotective effect of phytoestrogens is, at least in part, due to its antioxidative activity.

\section{Results \\ I. Glycitein alleviates $A \beta$-induced paralysis in the transgenic $C$. elegans}

A relationship between the onset of $A \beta$ expression and paralysis behavior has been established in the temperature-inducible transgenic C. elegans strain CL4176 [35]. We first conducted the paralysis assay using this strain to determine the effects of the isoflavones on $A \beta$-induced toxicity in the organism. We have observed in an independent study that the same transgenic $C$. elegans fed with Ginkgo biloba extract EGb 761, known for its antioxidant properties and beneficial effect for dementia, exhibited a delayed paralysis at the concentration ranging from 10 to $500 \mu \mathrm{g} / \mathrm{ml}$, and this effect was not dose-dependent (data not shown). Age-synchronized C. elegans (CL4176, 100 worms/group) were fed with daidzein, glycitein, genistein or vehicle for $48 \mathrm{~h}$ prior to temperature up shift and then scored for paralysis. Figure $1 \mathrm{~A}$ is a time course of a paralysis assay comparing a transgenic control strain CL1175, which does not express $A \beta$, with the $A \beta$-expressing strain CL4176 to demonstrate the specificity of $A \beta$-expression induced paralysis. Figure $1 \mathrm{~B}$ and $1 \mathrm{C}$ represent paralysis in four groups of C. elegans CL4176 fed with one of the three different isoflavones $(100 \mu \mathrm{g} / \mathrm{ml})$ or vehicle. Apparently, $A \beta$-induced paralysis was delayed in worms fed with glycitein (Fig. 1B, filled circle compared with open squares, $n$ $=3$ assays, 100 worms/assay). Genistein, known to have more estrogenic activity than diadzein or glycitein [16], did not affect $A \beta$-induced paralysis in the nematode CL 4176 at the concentration applied (Fig. 1B filed squares, $\mathrm{n}$ $=3$ assays, 100 worms/assay). The $\mathrm{A} \beta$-induced paralysis was moderately accelerated at the end of the assay in the CL4176 worms fed with daidzein (Fig. 1B filled triangles, $\mathrm{n}=3$ assays, 100 worms/assay). Figure $1 \mathrm{C}$ shows a statistical analysis of the paralysis assays displayed in Fig. 1B. 
A Paralysis assay in C.elegans strains

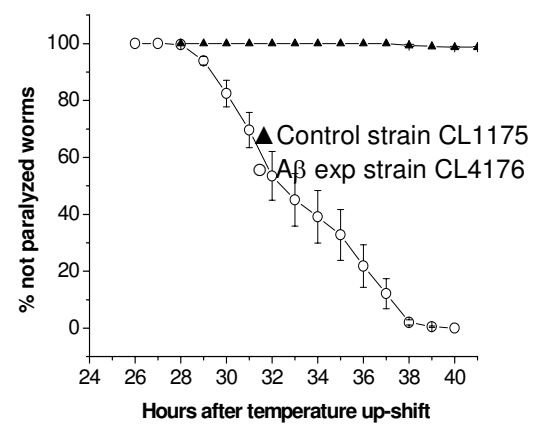

B Paralysis assay in C.elegans CL4176

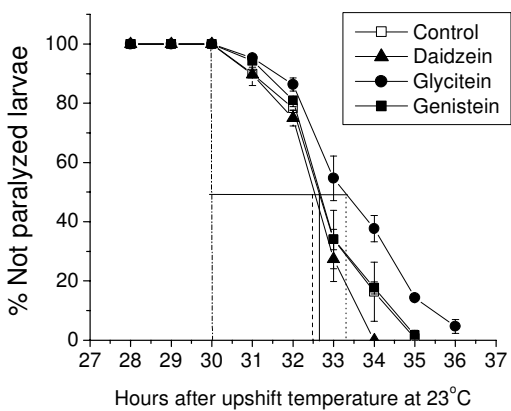

C Quantify paralysis assay

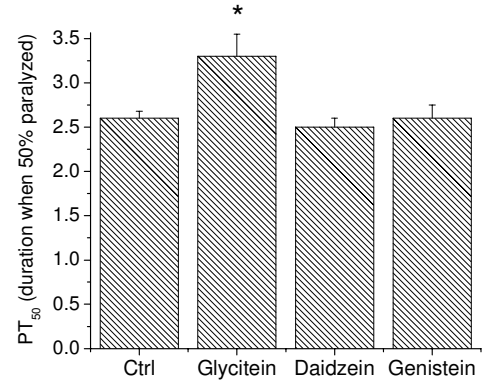

\section{Figure I}

Paralysis assays in the transgnic $C$. elegans. A. Time course of paralysis in the transgenic strain CL4I76 and the control strain CLII75. B. Paralysis assay in C. elegans CL4I76 fed with different isoflavones. Synchronized eggs were maintained at $16^{\circ} \mathrm{C}$ for $38 \mathrm{~h}$, on the $35 \times 10 \mathrm{~mm}$ culture plates ( 100 eggs/plate) containing vehicle (control), daidzein, glycitein, or genistein $(100 \mu \mathrm{g} / \mathrm{ml})$, followed by up-shifting the temperature to $23^{\circ} \mathrm{C}$ to induce the transgene expression. The paralysis was scored at 60 min intervals. Data are expressed as percentage of non-paralyzed worms from three independent assays of 100 worms in each experiment. $\mathbf{C}$. The paralysis assays were quantitated for mean time duration at which $50 \%$ worms were paralyzed from $30 \mathrm{hrs}$ after up shift temperature to $23^{\circ} \mathrm{C}\left(\mathrm{PT}_{50}\right)$. $\mathrm{P}$ values were obtained from 3 independent assays for the worms fed with different drugs each paired with untreated controls. Total 100 worms were used in each assay.
We define $\mathrm{PT}_{50}$ as time duration at which $50 \%$ worms were paralyzed from $30 \mathrm{hrs}$ after up shift of temperature to $23^{\circ} \mathrm{C}$. Statistically, a significant delay of $\mathrm{A} \beta$-induced paralysis was only observed in the worms fed with glycitein (Fig. 1C, Control, $\mathrm{PT}_{50}=2.6 \pm 0.08 \mathrm{~h}$ vs. Glycitein, $\mathrm{PT}_{50}=3.3 \pm 0.25$ h. $\mathrm{p}=0.036$; Daidzein, $\mathrm{PT}_{50}=2.5 \pm 0.10$ $\mathrm{h}, \mathrm{p}=0.46$; Genistein, $\mathrm{PT}_{50}=2.6 \pm 0.15 \mathrm{~h} . \mathrm{p}=0.76 ; \mathrm{n}=3$ assays each drug, 40 worms in each assay group). Although Daidzein accelerated paralysis at the end point, $\mathrm{PT}_{50}$ did not indicate significant difference (Fig 1C) compared with that of the controls. It is known that the effective concentration for genistein to activate the estrogen receptor and tyrosine kinases is much lower (nM). Differential concentration effects of genistein might contribute to protection against $A \beta$ toxicity/paralysis. Thus, we conducted experiments using genistein at two lower doses (10 $\mu \mathrm{g} / \mathrm{ml}$ and $0.1 \mu \mathrm{g} / \mathrm{ml}$ ). A $\beta$-induced paralysis was not affected in the worms fed with either of the two concentrations (data not shown), supporting the view that the effect of glycitein is specific.

To determine the overall effect of the isoflavones on the behavioral of the C. elegans, we conducted oxidative stress sensitivity assay and life span assay. We found that the $C$. elegans fed with glycitein were more resistant toward an oxidative stressor Juglone than the worms fed with daidzein and genistein (data not shown). However, the maximum life span was not affected in the C. elegans CL2006 fed with glycitein compared with untreated control worms (data not shown).

\section{Glycitein attenuates levels of $\mathrm{H}_{2} \mathrm{O}_{2}$ in the $A \beta$-expressing C. elegans \& in vitro}

Given that soy isoflavones are potent antioxidants, we determined whether the antioxidative properties of the isoflovones might contribute to protection against $\mathrm{A} \beta$-toxicity. Previously, we established an in vivo assay for the measurement of intracellular $\mathrm{H}_{2} \mathrm{O}_{2}$-associated ROS in $C$. elegans [36]. The transgenic C. elegans were fed with or without the isoflavones, prior to induction of $A \beta$-expression, followed by measurement of the levels of $\mathrm{H}_{2} \mathrm{O}_{2}$ in the organism. Figure 2A demonstrates that the levels of ROS in the C. elegans CL2006 fed with glycitein for $36 \mathrm{~h}$ were reduced (control $100 \pm 23 \%$, glycitein $68.9 \pm 7 \%$, n $=3, p=0.05)$. Although genistein increased the levels of ROS compared with the untreated controls (Ctrl $100 \pm 23$ $\%$, genistein $126.1 \pm 18 \%, \mathrm{n}=3, \mathrm{p}=0.28$ total 300 worms in each group), it is not statistically significant. Daidzein did not affect $A \beta$-induced elevation of ROS (Ctrl $100 \pm$ $23 \%$, daidzein $104.4 \pm 6 \%, n=6, p=0.74)$. These results suggest the decreased $A \beta$ toxicity by glycitein might be, in part, a consequence of its antioxidative action.

To confirm the scavenging effect of glycitein on different species of oxidative free radicals in vitro, we first measured 


\section{A Levels of $\mathrm{H}_{2} \mathrm{O}_{2}$ in C.elegans CL2006}
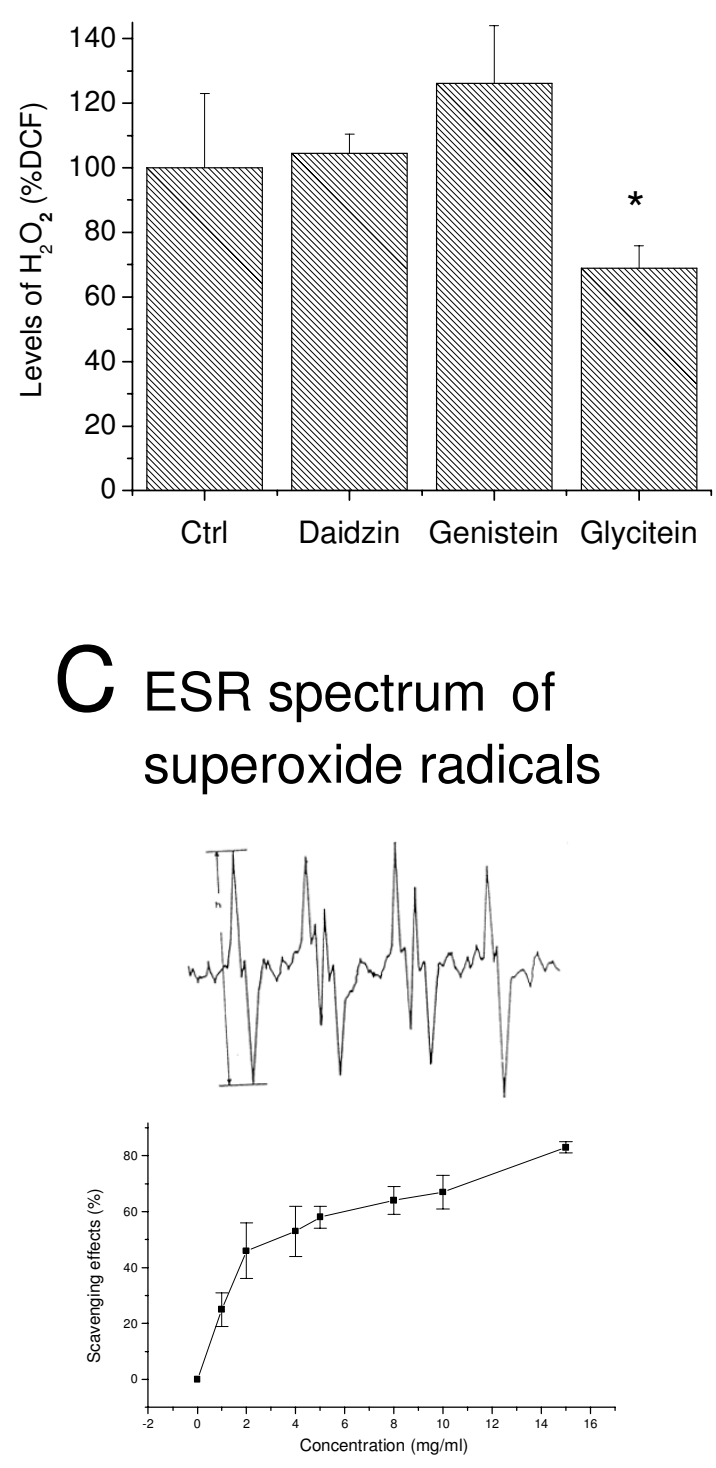

\section{B ESR spectrum of hydroxyl radicals}
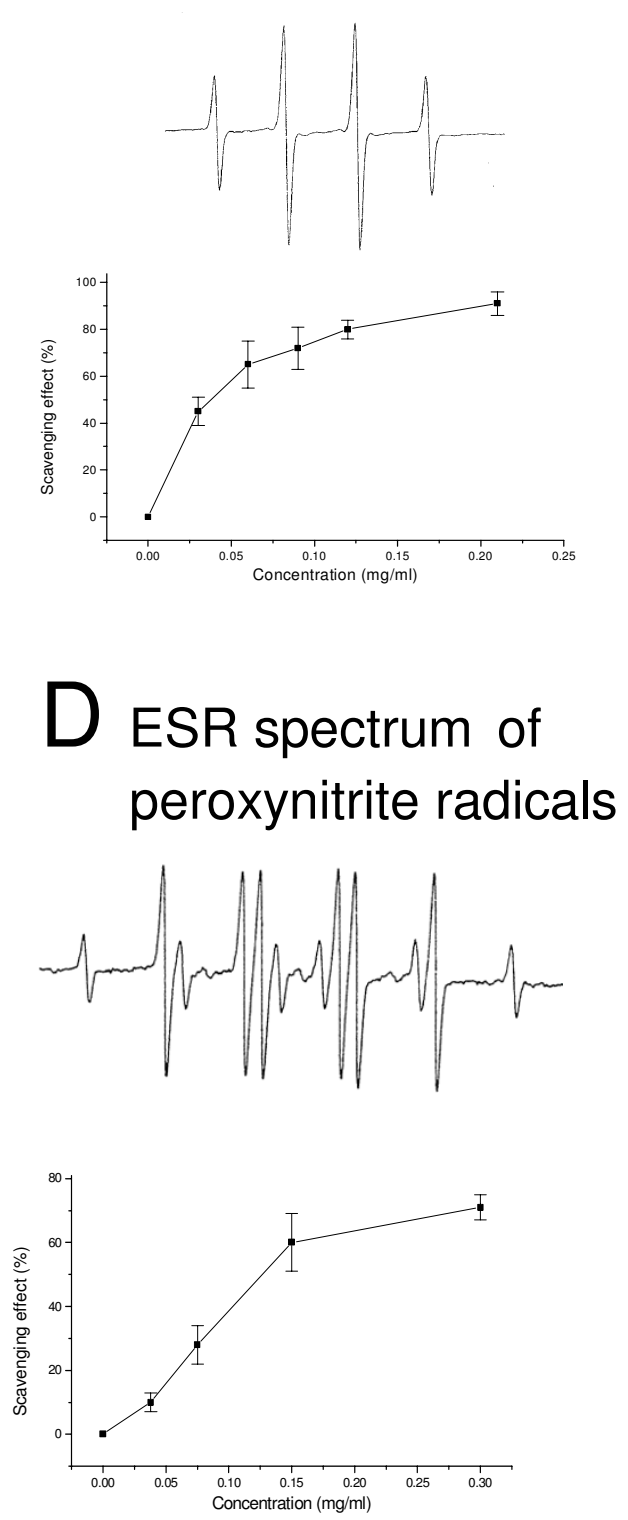

\section{Figure 2}

Scavenging effect of glycitein in the transgenic $C$. elegans and in vitro. A. $\mathrm{H}_{2} \mathrm{O}_{2}$ level in transgenic $\mathrm{C}$. elegans $\mathrm{CL} 476$ fed with different isoflavones. $\mathrm{C}$. elegans strain CL4I76 was maintained at $16^{\circ} \mathrm{C}$ for $38 \mathrm{~h}$ and then temperature up-shifted to $23^{\circ} \mathrm{C}$ for $48 \mathrm{~h}$, followed by measurement of $\mathrm{H}_{2} \mathrm{O}_{2}$ (DCF assay described in methods). CL4I76 worms were fed vehicle (Ctrl), $100 \mu \mathrm{g} / \mathrm{ml}$ daidzein, genistein or glycitein from I day of age until 3 days of age. At least 60 worms from each group were analyzed for levels of $\mathrm{H}_{2} \mathrm{O}_{2}$. Results are expressed as a percentage of fluorescence (\%DCF) relative to control. B. Scavenging effect of glycitein on hydroxyl radicals in vitro. The ESR conditions: X-band, $100 \mathrm{kHz}$ modulation with amplitude I G, microwave power $10 \mathrm{~mW}$, central magnetic field $3,250 \mathrm{G}$, sweep width $200 \mathrm{G}$, temperature $20^{\circ} \mathrm{C}$. Inset: ESR spectrum of DMPO-OH generated from Fenton reaction and trapped by DMPO. C. Scavenging effect of glycitein on superoxide radicals in the system. The ESR conditions are the same as in Fig. 3B. Inset: ESR spectrum of DMPO-OOH generated from Xanthine/xanthine oxidase and trapped by DMPO; D. Scavenging effect of Soy isoflavone glycitein on. $\mathrm{CH}_{3}$ free radicals in the in vitro system. Inset: ESR spectrum of $\mathrm{CH}_{3}$-tNB generated from the oxidation of DMSO by ONOO-and trapped by $\mathrm{tNB}$. 
its effect on hydroxyl radicals. The hydroxyl free radicals were generated from Fenton reaction $\left(\mathrm{H}_{2} \mathrm{O}_{2} 3 \%, \mathrm{FeSO}_{4}\right.$ $0.1 \mathrm{mM}$ and tapped by DMPO $(0.1 \mathrm{~mol} / \mathrm{l})$. A spectrum with 4 lines and 1:2:2:1 intensity $\left(g=2.0045, a_{N}=a_{H}=\right.$ 14.9 G) were obtained (Fig. 2B). Figure 2B demonstrates the signal intensity decrease with different concentrations of the soy isoflavone glycitein added into this system. The soy isoflavone glycitein appears to have very strong scavenging effects on hydroxyl radical generated from Fenton reaction $\left(\mathrm{IC}_{50}=0.035 \mathrm{mg} / \mathrm{ml}\right)$.

We then determined the scavenging effect of glycitein on superoxide free radicals. The superoxide free radicals were generated from xanthine/xanthine oxidase and trapped by DMPO. A signal with 12 lines $\left(\mathrm{a}_{\mathrm{N}}=14.2 \mathrm{G}_{,} \mathrm{a}_{\mathrm{H}}{ }^{\beta}=11.2 \mathrm{G}\right.$, $\mathrm{a}_{\mathrm{H}} \gamma=1.3 \mathrm{G}$ ) was obtained (Fig. 2C), and it was decreased with addition of glycitein as shown in Fig. 2C. Apparently, soy isoflavone glycitein has moderate scavenging effect on superoxide free radicals generated from the reaction of xanthine/xanthine oxidase $\left(\mathrm{IC}_{50}=2 \mathrm{mg} / \mathrm{ml}\right)$.

The reaction of NO with superoxide free radicals is very fast $\left(6.4 \times 10^{9} \mathrm{~mol} / \mathrm{L}^{-1} \mathrm{~s}^{-1}\right)$ and forms peroxynitrite (ONOO-). In alkaline solution, it is stable but has a pKa of 6.6 at $0^{\circ} \mathrm{C}$ and decays rapidly once protonated, to hydroxyl radical-like species and $\mathrm{NO}_{2}$, which can oxidize sulfhydryls and membrane lipid causing cell toxicity and some diseases. To determine the scavenging effects of the soy isoflavone glycitein on $\mathrm{ONOO}^{-}$, the methyl free radical was generated from the oxidation of DMSO by $\mathrm{ONOO}^{-}$and trapped by tNB and a spectrum with 12 lines $\left(a_{\mathrm{N}}=17.2 \mathrm{G}, \mathrm{a}_{\mathrm{H}}=14.2 \mathrm{G}\right)$ (Zhao et al. 1996) was obtained (Fig. 2D). A strong scavenging effect of glycitein on ONOO- $^{-}\left(\mathrm{IC}_{50}=0.13 \mathrm{mg} / \mathrm{ml}\right)$ was found as shown in Fig. 2D.

\section{3. $\beta$ amyloid were significantly reduced in transgenic $C$. elegans fed with glycitein}

The modified "amyloid hypothesis" states that $\mathrm{A} \beta$ induced oxidative stress may speed up $\beta$ amyloid formation and lead to neuronal cell death in $\mathrm{AD}$ [37]. To determine whether soy isoflavones affect $\beta$ amyloid formation in vivo, we measured $\beta$ amyloid in the transgenic $C$. elegans CL2006 by thioflavin S staining. $\beta$ amyloid was stained and the fluorescent images were quantified. Quantitatively (Fig. 3), the mean numbers of $\beta$ amyloid staining per head area of the nematode are significantly reduced only in the transgenic C. elegans (CL2006) fed with glycitein $(4.1 \pm 0.4)$ compared with unfed controls $(6.9 \pm$ $0.5)$. A moderate reduction, although not significant, was observed in the C. elegans fed with genistein $(6.1 \pm 0.5)$. No change of $A \beta$ deposits was observed in the worms fed with daidzein $(6.9 \pm 0.6)$. None of the three soy isoflavones inhibited $A \beta$ aggregation in vitro (data not shown), suggesting that the decreased $\beta$ amyloid by glycitein in the

\section{A $\beta$ amyloid staining (CL2006)}
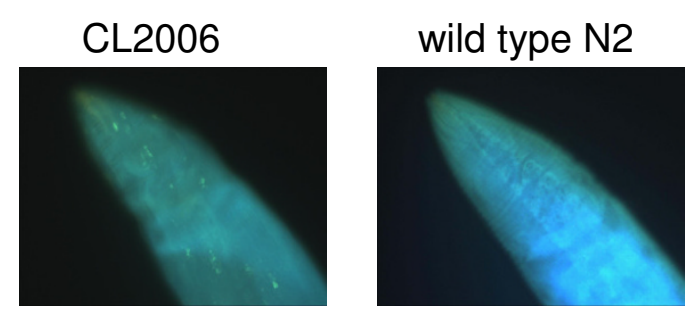

\section{B quantitative $\beta$ amyloid (CL2006)}

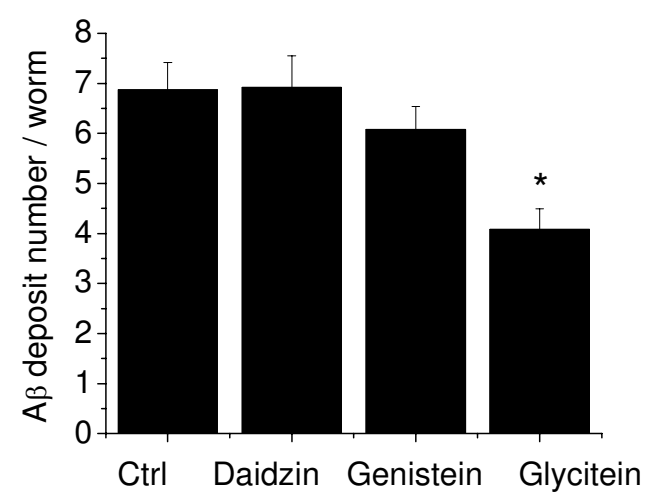

Figure 3

Effect of soy isoflavones on $A \beta$ deposits in transgenic $C$. elegans. A. Representative images of thioflavin $S$ staining in the transgenic (left) or wild type (right) worms. B. Quantitative $A \beta$ formation. $\beta$ amyloid were stained with thioflavin $S$ in $C$. elegans CL2006 fed with or without isoflavones $(100 \mu \mathrm{g} / \mathrm{ml})$ for 4 days starting at the second day of age. $\beta$ amyloid were examined using a fluorescence microscope. The quantity of $\beta$ amyloid is expressed as mean number of $A \beta$ deposits/worm head area $(n=24)$.

transgenic C. elegans (Fig. 1) is not due to its direct binding to $A \beta$, but might be a consequence of its antioxidative action (Fig. 2).

\section{Discussion}

In this study, we employed a transgenic C. elegans model to evaluate the pharmacological effect of the soy-derived isoflavones genistein, glycitein and daidzein, on A $\beta$-initiated toxicity and oxidative stress. Results of these assays indicate that among the three isoflavones tested, glycitein delayed $A \beta$ induced paralysis and attenuated the levels of amyloid formation in the transgenic C. elegans. In 
addition, glycitein significantly scavenged hydroxyl free radicals and inhibited the oxidation of peroxynitrite in vitro.

There has been strong evidence for the neuroprotective role of estrogen in aging animal studies and human studies $[8,11,26,38-42]$. Evidence for estrogens effect on cognition in women with $\mathrm{AD}$ is controversial $[10,14]$. However, it was reported that ovariectomized guinea pigs had a pronounced accumulation of $\beta$-amyloid plaques compared to intact controls and that estrogen replacement reversed the accumulation [3]. A proposed mechanism for estrogen inhibition of plaque formation is that estrogen induces the cleavage of membranous amyloid precursor protein (APP) generating a soluble proteolytic fragment that precludes the development of $\beta$-amyloid plaque formation $[5,6]$. The possible link between estrogen and $A \beta$ prompted us to determine the effect of phytoestrogens on $A \beta$-induced toxicity in a model organism. Knowing that apl-1, the member of APP family in $C$. elegans, lacks a recognizable $A \beta$ sequence $[57,58]$, the effect of phytoestrogens may have different mechanisms of action. Phytoestrogens have received increasing attention due to their potential protective effects against agerelated diseases and hormone-dependent cancers. Phytoestrogens have the ability to selectively activate estrogen receptors, thus affecting many of the biological responses that are caused by endogenous levels of estrogen without concurrent and undesired side effects. Phytoestrogens may act both as an agonist and antagonist in a tissue specific manner [4]. It was suggested that phytoestrogenes can significantly influence sexually dimorphic cognitive behavior by enhancing spatial memory in young adult female animals but inhibit this ability in male [4].

Our observation that glycitein, with weaker estrogenic activities than genistein and daidzein, inhibited $A \beta$ induced paralysis and deposition, suggests that neuroprotection by phytoestrogens may not be mediated through the estrogenic activity of the compounds. Compared to other soy isoflavones, the estrogenic activity of glycitein is 20 times lower than genistein and daidzein and 200 times lower than $17 \beta$ estradiol [16]. Soybeans contain large amounts of glycitein and its glycosides, which have been reported to inhibit growth and DNA synthesis of smooth muscle cells [23].

Apparently, it is the antioxidant activity that contributed to the protective effect by glycitein against $\mathrm{A} \beta$-toxicity (Fig. 1 ) since glycitein is the only soy isoflavone which significantly attenuated the levels of ROS in the C. elegans (Fig. 2 ). Oxidative free radicals have been postulated as a cause of aging and of some degenerative diseases $[45,46]$. The formation of free radicals by $A \beta$ in vitro [46] and profound induction of protein carbonyl in the transgenic C. elegans suggests that $A \beta$-induced oxidative stress triggers $A \beta$ induced paralysis in the C. elegans [47]. Although $A \beta$ aggregations have been identified as neurotoxic to the brain, oxidative stress is predicted to occur before these aggregations [47] leading to cell apoptosis. Thus the observed reduction in amyloid formation might also be due to the anti-oxidant activities of glycitein. These observations go along with the free radical hypothesis of aging, which states that there is an imbalance of free radicals and reactive oxygen species (ROS) in the brain causing significant damage to key cellular components [45]. This imbalance may be the causative agent for the pathology of neurodegenerative disorders (such as $\mathrm{AD}$ ) since most of these disorders are associated with age [48]. The toxicity of free radicals depends on the kinetics of their production, as well as on their stability and transfer efficiency to lipids and proteins. These radicals may interact with other radicals to produce $A \beta$ aggregates [49], and promote the cleavage of the $A \beta$ precursor (APP) supporting the idea that $A D$ can be attributed to continuous oxidative stress, along with a weakened antioxidant status [49].

The causal relationship between ROS and $A \beta$ has been long debated in the field. The transgenic C. elegans would allow us to address the issue. We have conducted a paralysis assay in the C. elegans fed with vitamin C and EGb 761, a Ginkgo biloba leaf extract. Surprisingly, vitamin C alone did not delay $A \beta$-induced paralysis, but it did when combined with EGb 761, which also inhibits $A \beta$ oligomerization (data not shown), suggesting that it is the combined actions of antioxidants and other protection against $A \beta$ toxicity that is necessary for alleviating $A \beta$ induced paralysis. Thus, we consider that the antioxidant action is only partially contributing to the protection against $A \beta$ toxicity. Same argument may apply to the discrepancy of the genistein's effect between Fig 2A and Fig $3 \mathrm{~B}$; the increased levels of ROS by genistein did not correlate with a decreased $A \beta$ deposition. Defining a functional relationship between $A \beta$ deposition and toxicity, and ROS level is certainly one of our future directions.

The assumption that the protective effect by glycitein against $A \beta$ toxicity might not be mediated by its action on the estrogen receptor is supported by our observation that genistein, with strongest estrogenic activity among soy isoflavones, did not offer protection again $A \beta$-toxicity. Genistein is a known tyrosine kinase inhibitor. The effective concentration for genistein to activate the estrogen receptor and inhibit tyrosine kinases is much lower (nM$\mu \mathrm{M})$ than the concentration we applied to the worms [4] and [5]. These differential concentration effects of genitein might offer protection against $A \beta$ toxicity/paralysis. However, our additional experiments using much lower dosage of genistein did not provide evidence to support this notion. $\mathrm{A} \beta$-induced paralysis was not affected in the 
worms fed with either of the two lower concentrations. Since at the given concentration $(10 \mu \mathrm{g} / \mathrm{ml}$, i.e. $37 \mu \mathrm{M})$, we observed effects with glycitein but not genistein, we assume that they have differential effects on $A \beta$-induced paralysis. It has been shown that high dose of genistein $(\mu \mathrm{M})$ could cause apoptosis in rat primary cortical neurons in vitro via a calcium dependent pathway [43].

We demonstrated a consistent, correlative effect by glycitein against $A \beta$-induced toxicities using different assays, which suggests that $C$. elegans is a valid model for mechanistic examination of the transgene products as well as for pharmacological analysis of time course and kinetics of drug effect $[50,51]$. A relationship between $A \beta$ amino-acid sequence, amyloid formation and oxidative damage was established using this model. Yatin et al. [46] showed both in vitro and in the C. elegans model that methionine $\left(\mathrm{Met}^{35}\right)$ is critical for free radical production by $\mathrm{A} \beta_{1-42}$, and it is also critical for $\beta$-sheet formation in the transgenic C. elegans lines [52]. A correlation between a progressed paralysis phenotype with increased levels of protein carbonyls in CL4176 [47] supports the advanced "amyloid hypothesis" [37]. Mammalian $\alpha B$-crystallin (CRYAB) a stress-inducible chaperone protein, which inhibits fibril formation of $A \beta-(1-42)$ [53], has a protein homologue HSP-16 in the C. elegans. This protein has been reported to be colocalized with intracellular $A \beta$ and up regulated in the transgenic $A \beta$-expression strain of $C$. elegans [35]. We previously demonstrated that a neuroprotectant, EGb 761, an extract from the ginkgo biloba tree leave, suppressed HSP-16 expression [54]. Although many protein molecules including estrogenic receptors are conserved in the nematode [55], the lack of correlation between isoflavone estrogenic activity and suppression of $A \beta$ toxicity in this model system may not exclude the neuroprotection estrogen in AD patients. Nevertheless, it is likely that the temporal sequence of events manifested in the transgenic worms is the same as the one demonstrated in a Drosophila model of AD [56] in that accumulation of $A \beta_{42}$ in the brain is sufficient to cause cognitive impairment and neurodegeneration.

\section{Conclusion}

We used a transgenic $C$. elegans model to evaluate the pharmacological effect of the soy-derived isoflavones genistein, glycitein and daidzein, on $\mathrm{A} \beta$-initiated toxicity and oxidative stress. Among the three compounds tested, only glycitein alleviated $A \beta$ expression-induced paralysis in the transgenic $C$. elegans, which correlated with a reduced level of hydrogen peroxide and $\beta$ amyloid. These findings suggest that the neuroprotective effect of phytoestrogens is probably due, at least in part, to its antioxidative activities.

\section{Methods}

Soy isoflavones were obtained from the National Natural Products Research Center (Oxford, MS). Stock solutions of the soy isoflavones $(1 \mathrm{mg} / \mathrm{ml}, 1000 \times$ stock solution) were made in $100 \%$ ethanol. The final concentration of ethanol in the food did not exceed $0.01 \%$. DMPO $(5,5-$ dimethyl-1-pyroline-1-oxide, $\mathrm{tNB}(3,3,5,5$-tetramethylpyrroline N-oxide) were purchased from Sigma Chem Co. DMPO was purified by active charcoal.

\section{C. elegans strains}

The construction and characterization of the transgenic nematode strains CL2006 and CL4176 have been described previously [34,35]. The CL2006 strain constitutively produces a muscle-specific $A \beta_{1-42}$, whereas the expression of $A \beta_{1-42}$ in CL4176 depends on a temperature up-shift from 16 to $23^{\circ} \mathrm{C}$. Age-synchronized wild type (N2) and the transgenic CL2006 were propagated at $20^{\circ} \mathrm{C}$ in a temperature-controlled incubator (Sheldon Manufacturing, Model 2005, Cornelius, OR), CL4176 at $16^{\circ} \mathrm{C}$, on solid nematode growth medium (NGM) seeded with $E$. coli (OP50) for food. All chemicals for treatment of experimental animals were added directly to the OP50 food source and began when larvae were 2 days old (for CL2006). In most cases, the nematodes were treated for 4 days (after hatching) with their respective drug. In the life span assay, the $C$. elegans were treated with the drug for the duration of their lifetime.

\section{Paralysis assays}

C. elegans strain CL4176 [35,47] was maintained at $16^{\circ} \mathrm{C}$ and egg-synchronized onto $35 \times 10 \mathrm{~mm}$ culture plates containing vehicle or drug. The worms (100 worms on each plate) were allowed to grow for $38 \mathrm{~h}$ at $16^{\circ} \mathrm{C}$. After 38 hours the temperature was up shifted to $23^{\circ} \mathrm{C}$ to induce $A \beta$ expression. Paralysis was scored at $1 \mathrm{~h}$ intervals until all worms were paralyzed

\section{$\mathrm{H}_{2} \mathrm{O}_{2}$ assay in $\mathrm{C}$. elegans}

Intracellular levels of $\mathrm{H}_{2} \mathrm{O}_{2}$-related reactive oxidative species (ROS) were measured in C. elegans using 2,7-dichlorofluorescein diacetate (DCF-DA; Molecular Probes). At the end of the specified treatment times, the C. elegans were collected into $100 \mu \mathrm{l}$ phosphate buffered saline (PBS) (molarity) with 1\% Tween-20 (PBST) in eppendorf tubes. The worms were then sonicated (Branson Sonifier 250, VWR Scientific, Suwanee, GA) and pipetted into wells of 96-well plates containing DCF-DA (final concentration $50 \mu \mathrm{M}$ in PBS). Samples were read every $10 \mathrm{~min}$ for 2.5 h. in an FLx800 Microplate Fluorescent Reader (BioTek Instruments, Winooski, VT) at $37^{\circ} \mathrm{C}$ at excitation 485 $\mathrm{nm}$ and emission $530 \mathrm{~nm}$. 


\section{ESR assay of free radicals}

In order to measure the effect of glycitein on free radicals, the spin trap and the system-generated free radicals were mixed and measured with ESR spectrometer and the signal intensity was taken as Ho. Then the system with addition of glycitein was measured again. Hydroxyl radicals $\left(\mathrm{H}_{2} \mathrm{O}_{2} 3 \%\right), \mathrm{Fe}_{2} \mathrm{SO}_{4}(0.1 \mathrm{mM})$ and DMPO $(0.1 \mathrm{~mol} / \mathrm{l})$ were mixed and sucked into a quartz capillary for ESR measurement, and the signal intensity was taken as $\mathrm{Hx}$. The scavenging effect was calculated by $[(\mathrm{Ho}-\mathrm{Hx}) / \mathrm{Ho}] \times$ $100 \%$. The ESR spectra were recorded with Brucker ER200 D-SRC ESR spectrometer. Parameters were employed as follows: X-band, $100 \mathrm{kHz}$ modulation with amplitude 1 $\mathrm{G}$, microwave power $10 \mathrm{~mW}$, central magnetic field 3,250 $\mathrm{G}$, sweep width $200 \mathrm{G}$, temperature $20^{\circ} \mathrm{C}$.

\section{Fluorescent staining and quantitation of $\beta$ amyloid}

Individual CL2006 transgenic nematodes were fixed in $4 \%$ paraformaldehyde/PBS, $\mathrm{pH} 7.4$, for $24 \mathrm{~h}$ at $4{ }^{\circ} \mathrm{C}$, and then permeabilized in $5 \%$ fresh $\beta$-mercaptoethanol, $1 \%$ Triton X-100, $125 \mathrm{mM}$ Tris $\mathrm{pH} 7.4$, in a $37^{\circ} \mathrm{C}$ incubator for $24 \mathrm{~h}$. The nematodes were transferred, stained with $0.125 \%$ thioflavin S (Sigma) in 50\% ethanol for $2 \mathrm{~min}$, destained for 2 min in 50\% ethanol, washed with PBS and mounted on slides for microscopy. Fluorescence images were acquired using a $40 \times$ objective of a fluorescence microscope (BX 60, Olympus, Tokyo, Japan) equipped with a digital camera (Micropublisher 5.0, QIMAGING, Burnaby BC, Canada). The Thioflavin S-reactive deposits anterior of the pharyngeal bulb in individual animals were scored.

\section{Statistical analyses}

All statistical tests were performed using a PC-based version of the statistical program Origin 6.0 software (Microcal Software, Inc., Northampton, MA). Statistical comparisons between treatments were done with unpaired student t-test. All figures indicate means and standard error of the mean. Differences with a $p$ value less than 0.05 were defined as statistically significant.

\section{List of abbreviations used}

$\mathrm{AD}$, Alzheimer's disease

ROS, reactive oxygen species

$\mathrm{H}_{2} \mathrm{O}_{2}$, hydrogen peroxide

A $\beta$, beta amyloid peptide

ERT, Estrogen Replacement Therapy

SERMs, Selective Estrogen Receptor Modulators

\section{Authors' contributions}

AGZ carried out the paralysis assay, the oxidative stress assay and measurement of levels of ROS. MB conducted some of the oxidative stress assays. ZW performed the fluorescence staining for $A \beta$ deposits and the qantitation; JW performed additional experiments for the revision; IK provided the soy isoflavones; CL generated the transgenic C. elegans; BZ participated in the design and analysis of the experiments regarding in vitro assay of ROS; YL participated in the general design of the study, organized collaboration as well as finalizing the manuscript. All authors have read and approved the final manuscript.

\section{Acknowledgements}

This study was supported by The Mississippi Functional Genomic Network from a NIH-NCRR grant P20RR64I76 (YL and RS), by NIH grant ROIAT00 I928-0IAI from NIH National Center for Complimentary and Alternative Medicine (YL), and by a grant from the National Natural Science Foundation of P. R. China (BZ).

\section{References}

I. Behl C, Skutella T, Lezoualc'h F, Post A, Widmann M, Newton CJ, Holsboer F: Neuroprotection against oxidative stress by estrogens: structure-activity relationship. Mol Pharmacol 1997, 5 I:535-54 I.

2. $\mathrm{Li} R$, Shen $Y$ : Estrogen and brain: synthesis, function and diseases. Front Biosci 2005, 10:257-267.

3. Gandy S: Estrogen and neurodegeneration. Neurochem Res 2003, 28:1003-1008.

4. Lund TD, West TW, Tian LY, Bu LH, Simmons DL, Setchell KD, Adlercreutz $H$, Lephart ED: Visual spatial memory is enhanced in female rats (but inhibited in males) by dietary soy phytoestrogens. BMC Neurosci 200I, 2:20.

5. Goodman Y, Bruce AJ, Cheng B, Mattson MP: Estrogens attenuate and corticosterone exacerbates excitotoxicity, oxidative injury, and amyloid beta-peptide toxicity in hippocampal neurons. J Neurochem 1996, 66:1836-1844.

6. Kim H, Bang OY, Jung MW, Ha SD, Hong HS, Huh K, Kim SU, MookJung I: Neuroprotective effects of estrogen against beta-amyloid toxicity are mediated by estrogen receptors in cultured neuronal cells. Neurosci Lett 2001, 302:58-62.

7. Mook-Jung I, Joo I, Sohn S, Kwon HJ, Huh K, Jung MW: Estrogen blocks neurotoxic effects of beta-amyloid $(1-42)$ and induces neurite extension on BI03 cells. Neurosci Lett 1997, 235: $101-104$.

8. Green PS, Simpkins JW: Neuroprotective effects of estrogens: potential mechanisms of action. Int J Dev Neurosci 2000, I 8:347-358.

9. Cordey M, Gundimeda U, Gopalakrishna R, Pike C): Estrogen activates protein kinase $\mathbf{C}$ in neurons: role in neuroprotection. $J$ Neurochem 2003, 84: I340-1348.

10. Yoon BK, Kim DK, Kang Y, Kim JW, Shin MH, Na DL: Hormone replacement therapy in postmenopausal women with Alzheimer's disease: a randomized, prospective study. Fertil Steril 2003, 79:274-280.

II. Zec RF, Trivedi MA: The effects of estrogen replacement therapy on neuropsychological functioning in postmenopausal women with and without dementia: a critical and theoretical review. Neuropsychol Rev 2002, 1 2:65-109.

12. LeBlanc ES, Janowsky J, Chan BK, Nelson HD: Hormone replacement therapy and cognition: systematic review and metaanalysis. Jama 2001, 285: |489-|499.

13. Mulnard RA, Cotman CW, Kawas C, van Dyck CH, Sano M, Doody R, Koss E, Pfeiffer E, Jin S, Gamst A, Grundman M, Thomas R, Thal LJ: Estrogen replacement therapy for treatment of mild to moderate Alzheimer disease: a randomized controlled trial. Alzheimer's Disease Cooperative Study. Jama 2000, 283:1007-1015. 
14. Thal LJ, Thomas RG, Mulnard R, Sano M, Grundman M, Schneider L Estrogen levels do not correlate with improvement in cognition. Arch Neurol 2003, 60:209-2I2.

15. Zec RF, Trivedi MA: Effects of hormone replacement therapy on cognitive aging and dementia risk in postmenopausal women: a review of ongoing large-scale, long-term clinical trials. Climacteric 2002, 5: I22- I34.

16. Song TT, Hendrich S, Murphy PA: Estrogenic activity of glycitein, a soy isoflavone. J Agric Food Chem 1999, 47:1607-1610.

17. Zhao L, Chen Q, Diaz Brinton R: Neuroprotective and neurotrophic efficacy of phytoestrogens in cultured hippocampal neurons. Exp Biol Med (Maywood) 2002, 227:509-5I9.

18. Tikkanen MJ, Wahala K, Ojala S, Vihma V, Adlercreutz H: Effect of soybean phytoestrogen intake on low density lipoprotein oxidation resistance. Proc Natl Acad Sci U S A 1998, 95:3 I06-31 I0.

19. Zeng $\mathrm{H}$, Chen $\mathrm{Q}$, Zhao B: Genistein ameliorates beta-amyloid peptide (25-35)-induced hippocampal neuronal apoptosis. Free Radic Biol Med 2004, 36: I80-188.

20. Murphy PA, Farmakalidis E, Johnson LD: Isoflavone content of soya-based laboratory animal diets. Food Chem Toxicol 1982, 20:315-317.

21. Carroll KK: Review of clinical studies on cholesterol-lowering response to soy protein. I Am Diet Assoc 1991, 9 I:820-827.

22. Anthony MS, Clarkson TB, Williams JK: Effects of soy isoflavones on atherosclerosis: potential mechanisms. Am J Clin Nutr 1998 68: I390S-1393S

23. Pan W, Ikeda K, Takebe M, Yamori Y: Genistein, daidzein and glycitein inhibit growth and DNA synthesis of aortic smooth muscle cells from stroke-prone spontaneously hypertensive rats. J Nutr 200I, I 3 I: I I54- I I58.

24. Santell RC, Kieu N, Helferich WG: Genistein inhibits growth of estrogen-independent human breast cancer cells in culture but not in athymic mice. J Nutr 2000, I30: I665-1669.

25. Kuiper GG, Lemmen JG, Carlsson B, Corton JC, Safe SH, van der Saag PT, van der Burg B, Gustafsson JA: Interaction of estrogenic chemicals and phytoestrogens with estrogen receptor beta. Endocrinology 1998, 139:4252-4263.

26. Fillit HM: The role of hormone replacement therapy in the prevention of Alzheimer disease. Arch Intern Med 2002 162:1934-1942

27. Miltyk W, Craciunescu CN, Fischer L, Jeffcoat RA, Koch MA, Lopaczynski W, Mahoney C, Crowell J, Paglieri J, Zeisel SH: Lack of significant genotoxicity of purified soy isoflavones (genistein, daidzein, and glycitein) in 20 patients with prostate cancer. Am J Clin Nutr 2003, 77:875-882.

28. Brookmeyer R, Gray S, Kawas C: Projections of Alzheimer's disease in the United States and the public health impact of delaying disease onset. Am J Public Health I998, 88: |337-|342.

29. Price DL, Sisodia SS, Borchelt DR: Alzheimer disease--when and why? Nat Genet 1998, I9:314-316.

30. Selkoe DJ: Alzheimer's disease: genotypes, phenotypes, and treatments. Science 1997, 275:630-631.

31. Hardy J, Selkoe DJ: The amyloid hypothesis of Alzheimer's disease: progress and problems on the road to therapeutics. Science 2002, 297:353-356.

32. Mann DM: Cerebral amyloidosis, ageing and Alzheimer's disease; a contribution from studies on Down's syndrome. Neurobiol Aging 1989, 10:397-9; discussion 4I2-4.

33. Sherrington R, Rogaev El, Liang $Y$, Rogaeva EA, Levesque G, Ikeda M Chi H, Lin C, Li G, Holman K, et al.: Cloning of a gene bearing missense mutations in early-onset familial Alzheimer's disease. Nature 1995, 375:754-760.

34. Link CD: Expression of human beta-amyloid peptide in transgenic Caenorhabditis elegans. Proc Natl Acad Sci U S A 1995, 92:9368-9372.

35. Link CD, Taft A, Kapulkin V, Duke K, Kim S, Fei Q, Wood DE, Sahagan BG: Gene expression analysis in a transgenic Caenorhabditis elegans Alzheimer's disease model. Neurobiol Aging 2003, 24:397-4I3.

36. Smith JV, Luo Y: Elevation of Oxidative Free Radicals in Alzheimer's Disease Models Can Be Attenuated by Ginkgo biloba Extract EGb 76 I. J Alzheimers Disease 2003, 5:287-300.

37. Butterfield DA: Amyloid beta-peptide [1-42]-associated free radical-induced oxidative stress and neurodegeneration in Alzheimer's disease brain: mechanisms and consequences. Curr Med Chem 2003, 10:2651-2659.
38. Lee SJ, McEwen BS: Neurotrophic and neuroprotective actions of estrogens and their therapeutic implications. Annu Rev Pharmacol Toxicol 2001, 41:569-591.

39. Wise PM, Dubal DB, Wilson ME, Rau SW, Bottner M, Rosewell KL: Estradiol is a protective factor in the adult and aging brain: understanding of mechanisms derived from in vivo and in vitro studies. Brain Res Brain Res Rev 200I, 37:313-319.

40. Wise PM, Dubal DB, Wilson ME, Rau SW, Bottner M: Minireview: neuroprotective effects of estrogen-new insights into mechanisms of action. Endocrinology 200I, I 42:969-973.

41. Roof RL, Hall ED: Gender differences in acute CNS trauma and stroke: neuroprotective effects of estrogen and progesterone. J Neurotrauma 2000, I 7:367-388.

42. Roof RL, Hall ED: Estrogen-related gender difference in survival rate and cortical blood flow after impact-acceleration head injury in rats. J Neurotrauma 2000, I 7: I I 55- I I69.

43. Harman D: Ageing: a theory based on free radical and radiation chemistry. J Gerontol 1957, 2:298-300.

44. Yatin SM, Varadarajan S, Link CD, Butterfield DA: In vitro and in vivo oxidative stress associated with Alzheimer's amyloid beta-peptide (1-42). Neurobiol Aging 1999, 20:325-30; discussion 339-42..

45. Drake J, Link CD, Butterfield DA: Oxidative stress precedes fibrillar deposition of Alzheimer's disease amyloid beta-peptide $(1-42)$ in a transgenic Caenorhabditis elegans model. Neurobiol Aging 2003, 24:415-420.

46. Christen Y, Maixent JM: What is Ginkgo biloba extract EGb 761? An overview--from molecular biology to clinical medicine. Cell Mol Biol 2002, 48:601-6II

47. Hensley K, Carney JM, Mattson MP, Aksenova M, Harris M, Wu JF, Floyd RA, Butterfield DA: A model for beta-amyloid aggregation and neurotoxicity based on free radical generation by the peptide: relevance to Alzheimer disease. Proc Natl Acad Sci U S A 1994, $91: 3270-3274$.

48. Linford NJ, Yang Y, Cook DG, Dorsa DM: Neuronal apoptosis resulting from high doses of the isoflavone genistein: role for calcium and p42/44 mitogen-activated protein kinase. J Pharmacol Exp Ther 200I, 299:67-75

49. Gutierrez-Zepeda A, Luo Y: Testing the amyloid toxicity hypothesis of alzheimer s disease in transgenic Caenorhabditis elegans model. Front Biosci 2004, 9:3333-3338.

50. Driscoll M, Gerstbrein B: Dying for a cause: invertebrate genetics takes on human neurodegeneration. Nat Rev Genet 2003, 4:181-194.

51. Fay DS, Fluet $A$, Johnson CJ, Link CD: In vivo aggregation of betaamyloid peptide variants. J Neurochem 1998, 71:1616-1625.

52. Fonte V, Kapulkin V, Taft A, Fluet A, Friedman D, Link CD: Interaction of intracellular beta amyloid peptide with chaperone proteins. Proc Natl Acad Sci U S A 2002, 99:9439-9444.

53. Strayer A, Wu Z, Christen Y, Link CD, Luo Y: Expression of small heat-shock protein Hsp I 6-2 in Caenorhabditis elegans is suppressed by ginkgo biloba extract EGb 76I. FASEB J 2003, 1 7:2305-2307.

54. Shao W, Halachmi S, Brown M: ERAPI40, a conserved tissuespecific nuclear receptor coactivator. Mol Cell Biol 2002, 22:3358-3372.

55. lijima K, Liu HP, Chiang AS, Hearn SA, Konsolaki M, Zhong Y: Dissecting the pathological effects of human Abeta40 and Abeta42 in Drosophila: a potential model for Alzheimer's disease. Proc Natl Acad Sci U S A 2004, I 0 I:6623-6628. 